
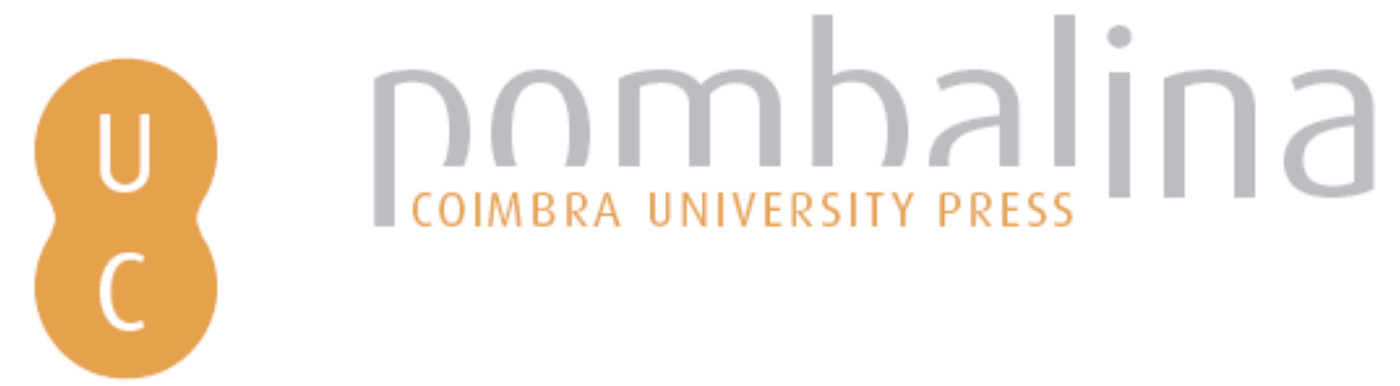

\title{
O sistema de gestão da llha de Moçambique: implementação da legislação na área do património edificado
}

\author{
Autor(es): Macamo, Solange \\ Publicado por: Imprensa da Universidade de Coimbra \\ URL \\ persistente: URI:http://hdl.handle.net/10316.2/44311 \\ DOI: $\quad$ DOI:https://doi.org/10.14195/978-989-26-1556-1_6 \\ Accessed : $\quad$ 26-Apr-2023 16:21:08
}

A navegação consulta e descarregamento dos títulos inseridos nas Bibliotecas Digitais UC Digitalis, UC Pombalina e UC Impactum, pressupõem a aceitação plena e sem reservas dos Termos e Condições de Uso destas Bibliotecas Digitais, disponíveis em https://digitalis.uc.pt/pt-pt/termos.

Conforme exposto nos referidos Termos e Condições de Uso, o descarregamento de títulos de acesso restrito requer uma licença válida de autorização devendo o utilizador aceder ao(s) documento(s) a partir de um endereço de IP da instituição detentora da supramencionada licença.

Ao utilizador é apenas permitido o descarregamento para uso pessoal, pelo que o emprego do(s) título(s) descarregado(s) para outro fim, designadamente comercial, carece de autorização do respetivo autor ou editor da obra.

Na medida em que todas as obras da UC Digitalis se encontram protegidas pelo Código do Direito de Autor e Direitos Conexos e demais legislação aplicável, toda a cópia, parcial ou total, deste documento, nos casos em que é legalmente admitida, deverá conter ou fazer-se acompanhar por este aviso.

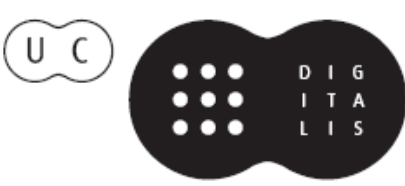




\section{OFICINAS DE \\ MUHIPITI \\ planeamento estratégico \\ património \\ desenvolvimento}

organização:

Walter Rossa

Nuno Lopes

Nuno Simão Gonçalves

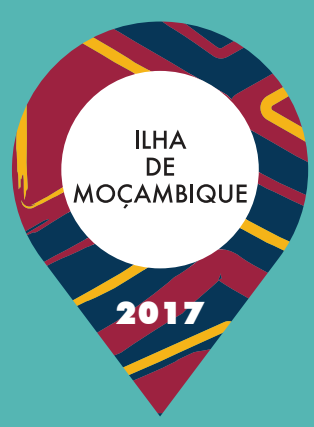




\title{
O SISTEMA DE GESTÃO DA ILHA DE MOÇAMBIQUE
}

\author{
Implementação da legislação \\ na área do património edificado
}

Solange Macamo

\section{INTRODUÇÃO: O SISTEMA DE GESTÃO DO PATRIMÓNIO CULTURAL}

O Plano de Gestão e Conservação da Ilha de Moçambique (20102014) (Jopela e Rakotomamonjy, 2014) define, no seu objetivo n. ${ }^{\circ}$ 1, a necessidade da entrada em vigor de um sistema de gestão do sítio de modo a conservar e valorizar o património cultural e natural da llha, salvaguardando o seu estatuto de sítio inscrito na Lista do Património Mundial da UNESCO. A exigência da salvaguarda desse estatuto da llha surge em cumprimento das condições da sua classificação, nomeadamente a integridade e a autenticidade.

De acordo com a UNESCO (2013), a expressão "sistema de gestão" pode ser entendida como uma série de processos que persegue um conjunto de resultados, alguns dos quais com retorno no sistema, e que permite o contínuo melhoramento das suas ações e realizações. Ndoro \& Kiriama (2008) utilizam a expressão "mecanismos de gestão", que podem ser formais ou informais, talvez no mesmo sentido que a designação aqui usada de "sistema de gestão".

Um sistema de gestão do património cultural ajuda a conservar e a gerir um dado imóvel ou conjunto de imóveis de maneira a proteger os valores do património, particularmente o seu Valor Universal Excecional, tratando-se de um bem do Património Mundial e, onde for possível, realça os seus amplos benefícios sociais, económicos e ambientais (UNESCO, 2013, tradução da autora). 


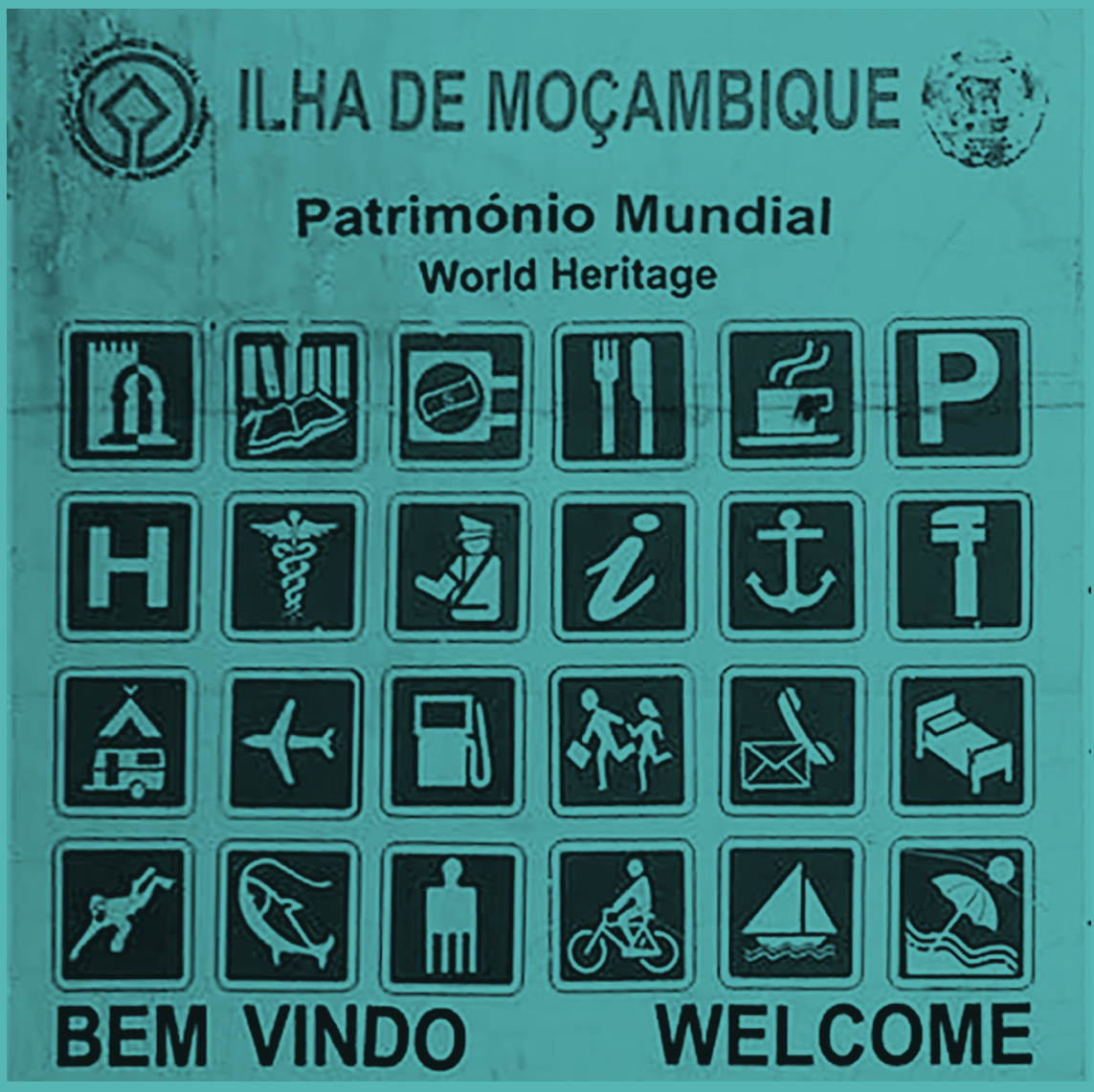

O conceito de valor universal excecional foi consolidado em 1972 pela Convenção sobre a Proteção do Património Mundial, Cultural e Natural da UNESCO. Esta convenção permitiu o entendimento de que determinados bens existentes no mundo são tão importantes que devem ser valorizados por toda a humanidade, cabendo a responsabilidade pela sua gestão a muitas nações, mesmo que a primeira responsabilidade seja de nações individuais (UNESCO, 2013: 29). Por isso, possuem significado cultural e/ou natural a valorizar pelas gerações atuais e futuras de toda a humanidade (Second Cycle of the World Heritage Periodic Reporting for Africa, 2010). Os pressupostos da Convenção foram formulados por um conjunto de países, visando a sua melhor implementação (Machado e Braga, 2010: 13). Alguns deles serão discutidos nas páginas seguintes. 


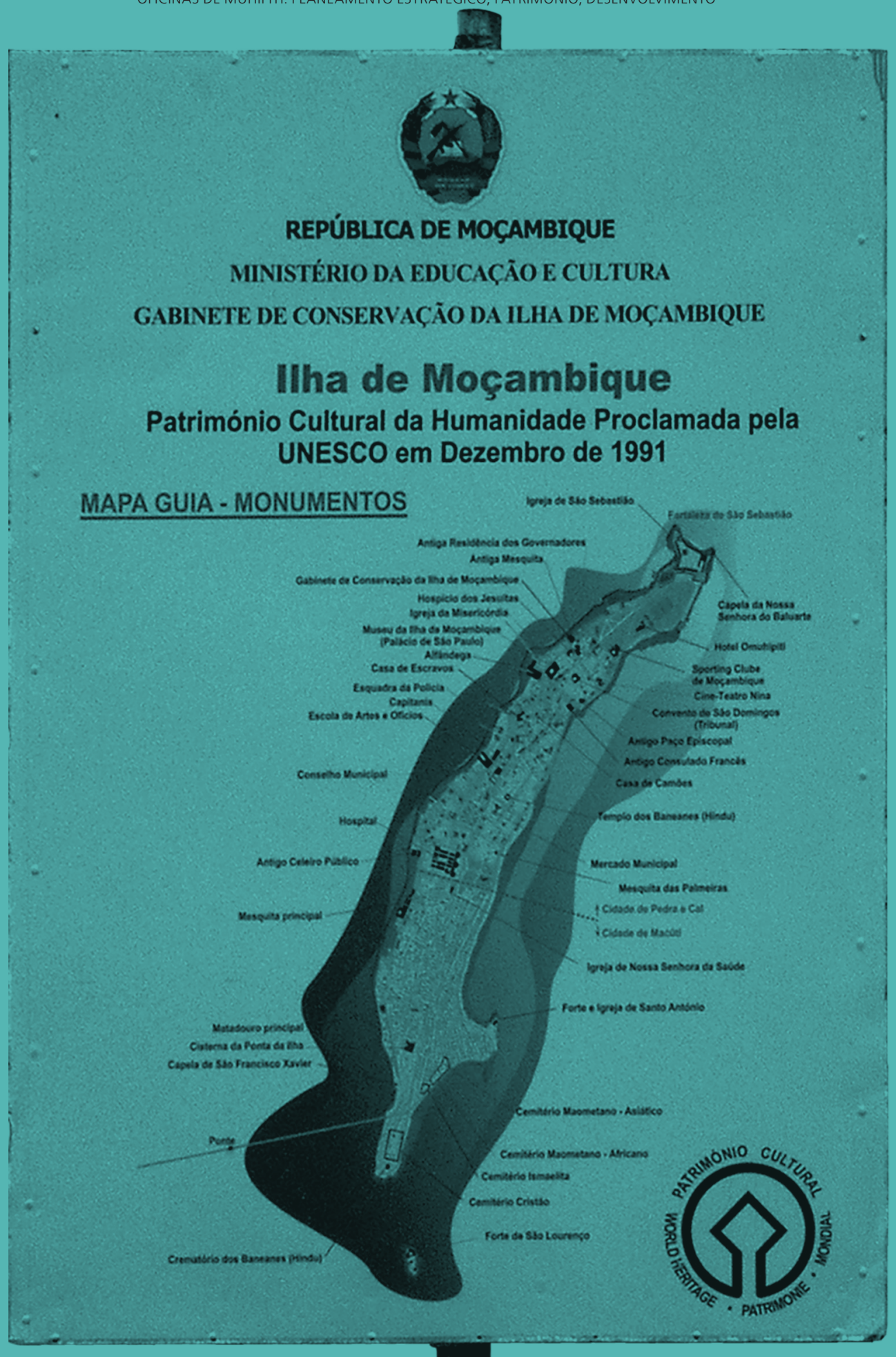




\section{A CONSTRUÇÃO DE UM SISTEMA ARTICULADO DE GESTÃO DO PATRIMÓNIO EDIFICADO}

\subsection{Introdução}

Em Moçambique existem mecanismos formais e informais que permitem a cristalização de um sistema de gestão do património edificado. Fazem parte dos mecanismos formais as instituições do governo, da base ao topo, através das ações programadas - Plano Anual de Atividades e Programa Quinquenal do Governo onde o património edificado é contemplado no contexto do património cultural. No caso dos mecanismos informais, são as comissões de gestão do património cultural que atuam a nível local, sobretudo nas zonas rurais onde, por exemplo, a gestão do património cultural é feita pelos líderes comunitários, por via da custódia tradicional (Jopela, 2006). O Governo de Moçambique tem uma política de monumentos que define prioridades para a conservação e gestão de monumentos, conjuntos e sítios (Resolução 12/2010, de 2 de junho). Esta política destaca a valorização dos monumentos para a educação e o turismo cultural, em benefício da sociedade, como formas de um sistema de gestão do património cultural. O Plano de Gestão da Ilha de Moçambique é implementado pelo Gabinete de Conservação da Ilha [GACIM]. O seu estatuto orgânico contempla uma comissão técnica, como órgão de aconselhamento, que agrega as instituições locais do governo, um representante da sociedade civil da Iha, assim como da UNESCO (Decreto n. ${ }^{\circ}$ 28/2006, de 13 de julho).

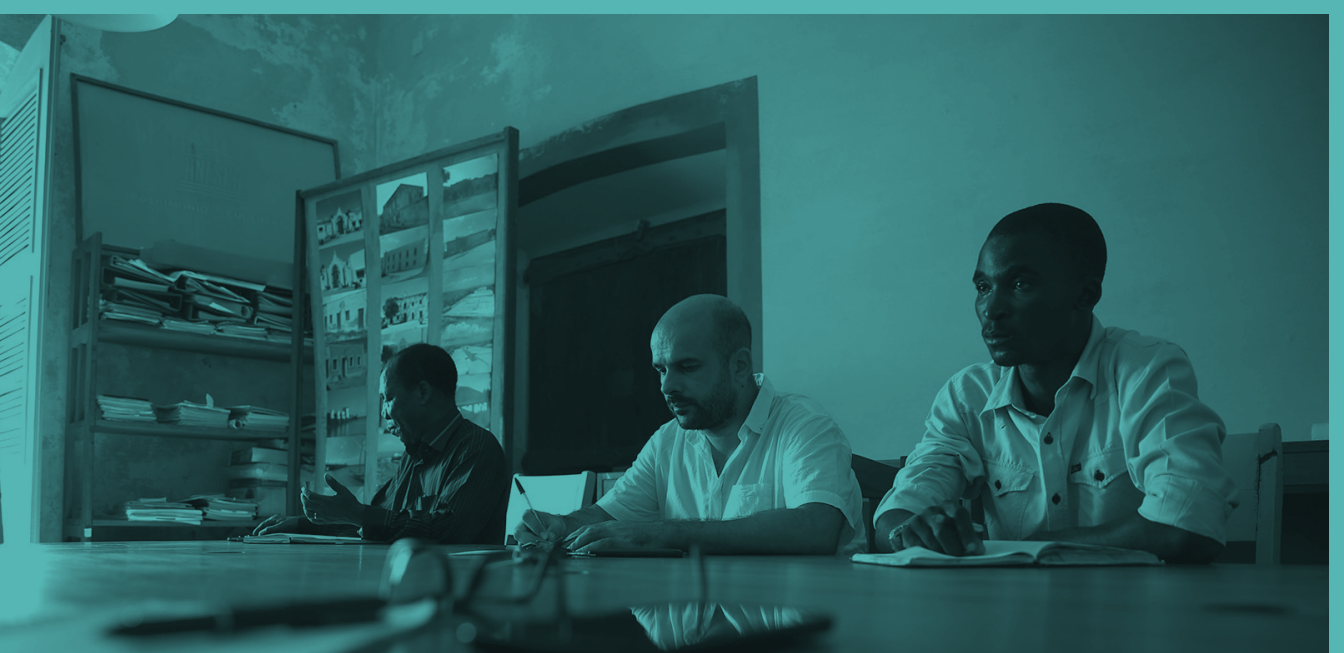


Nesta rubrica começarei por descrever os órgãos de gestão dos bens culturais imóveis a nível nacional, para, de seguida, apresentar o sistema articulado de gestão do património edificado, em particular para a llha, recorrendo à legislação.

\section{2. Órgãos de gestão}

O Regulamento sobre a Gestão dos Bens Culturais Imóveis (Decreto n. ${ }^{\circ}$ 55/2016, de 28 de novembro) prevê três níveis de gestão dos bens culturais imóveis:

i) a entidade superintendente da área da Cultura;

ii) o Conselho Nacional do Património Cultural;

iii) Comissões de Gestão. Os museus e os centros de interpretação podem, em determinadas circunstâncias, serem envolvidos pelo setor que superintende a área da cultura na gestão dos bens culturais imóveis, quando o seu perfil estiver relacionado com estes.

A entidade superintendente da área da cultura é o órgão do Estado responsável pela direção e coordenação da Política de Monumentos, a nível nacional, no que à gestão dos bens culturais imóveis diz respeito. Contudo, compete ao Conselho Nacional do Património Cultural, como órgão de consulta, emitir recomendações aos órgãos competentes sobre a proteção, financiamento e utilização dos bens culturais imóveis, entre outros. As comissões de gestão funcionam a nível local, sendo criadas pelas administrações de distrito e dos conselhos municipais, como depositários do património cultural (Lei 10/88, de 22 de dezembro), em coordenação com a entidade superintendente da área da cultura. As comissões de gestão, por atuarem a nível local, possuem maior relevância nesta comunicação, sendo a sua atividade aplicável ao caso da Ilha. Uma das suas responsabilidades é garantir que as comunidades locais, como depositárias legitimadas pelo direito costumeiro, sejam preferencialmente beneficiárias do uso do património cultural, no âmbito dos programas de educação e de turismo cultural (Decreto n. $55 / 2016$, de 28 de novembro). 


\subsection{Articulação do sistema de gestão do património edificado}

A articulação do sistema de gestão do património edificado está prevista no Decreto n. ${ }^{\circ}$ 55/2016, de 28 de novembro (com destaque para os arts. 39 e 42 sobre a gestão pública e privada de bens culturais imóveis, e sobre o uso compatível e sustentável de bens culturais imóveis, respetivamente).

Para o tema em questão, são relevantes os usos compatíveis aplicáveis para o património edificado da llha, entre outros, a educação, as atividades de pesquisa científica, o turismo, as atividades sociais (idem: art. 42).

Como acontece com outros bens do património cultural do país, a articulação do sistema de gestão do património edificado da llha é feita de acordo com a hierarquia estabelecida para o funcionamento dos ministérios, desde o nível central, provincial e distrital, com as devidas particularidades. Na llha funcionam dois principais órgãos de governo que são responsáveis pela gestão do património edificado: o Conselho Municipal, dependente do Ministério da Administração Estatal e Função Pública; e o GACIM, instituição do Ministério da Cultura e Turismo. As competências do GACIM estão detalhadas nos seus dois estatutos, específico (Decreto n. ${ }^{\circ}$ 27/ 2006) e orgânico (Decreto n. ${ }^{\circ}$ 28/2006) de 13 de agosto, como instituição responsável pela materialização das políticas do governo na área de conservação e gestão do património cultural e natural da Ilha. O diretor do GACIM, Celestino Girimula, em comunicação pessoal, enfatizou a necessidade de uma maior operacionalização destes instrumentos, designadamente através da clarificação de competências do GACIM na sua relação diária com os depositários e organismos de decisão a vários níveis, local e nacional. Neste contexto, o Regulamento sobre a Classificação e Gestão do Património Edificado e Paisagístico da Ilha de Moçambique (Decreto n. ${ }^{5}$ 5/2016, de 28 de novembro) específica, no seu artigo 4, que a proposta do uso do património edificado da ilha compete ao Município, em coordenação com o GACIM e com as partes interessadas. Contudo, a decisão sobre o seu uso compete ao setor que superintende a área da cultura, ouvido o Conselho Nacional do Património Cultural. Os artigos $41,42,43,48,51,52$ e 54 definem os procedimentos relacionados com a notificação, embargo ou demolição de obras, fiscalização, pagamento e atualização das multas, destino do valor das multas, a serem implementados de forma articulada. 


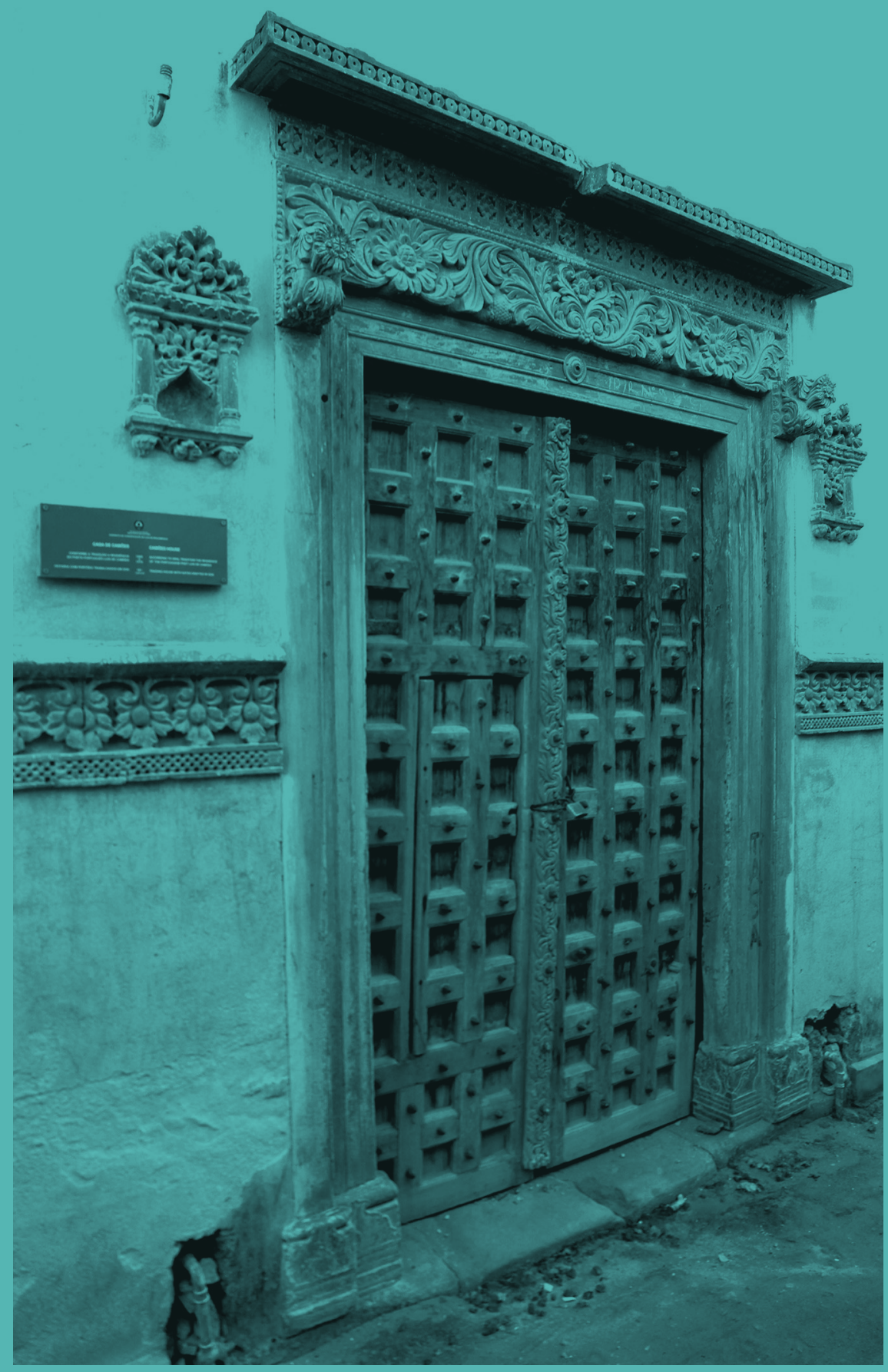




\section{A PRESERVAÇÃO DO VALOR UNIVERSAL EXCECIONAL DA ILHA DE MOÇAMBIQUE E AS CLASSES DO PATRIMÓNIO EDIFICADO}

\subsection{Introdução}

A área da llha de Moçambique classificada, inscrita na Lista do Património Mundial da UNESCO de acordo com os critérios iv) e vi), tem cerca de $1 \mathrm{~km}^{2}$ (fig. 1), perspetivando-se o alargamento da zona de proteção para o continente e a integração do Património Arqueológico Subaquático. Foi com base nesses critérios que foi também definido o valor universal excecional da llha de Moçambique, traduzido pela homogeneidade do seu tecido urbano, desde o século XVI até hoje.

O acompanhamento da UNESCO sobre a manutenção das condições da classificação do Património Mundial, como acontece com a llha, é feito através de relatórios periódicos e da monitorização reativa (Machado e Braga 2010: 18; Macamo 2014: 20). Cabe, por isso, aos gestores da Ilha acima referidos, prestar contas do trabalho realizado ao Centro do Património Mundial da UNESCO, pois esse é um dos deveres do Estado Moçambicano para que continue a manter as condições da sua inscrição, evitando, por conseguinte, ser integrada na Lista dos Bens em Perigo. Ao analisar as condições de integridade e autenticidade, importa fazer referência ao paradigma da conservação urbana que foi recentemente atualizado no âmbito da Recomendação sobre a Paisagem Urbana Histórica (UNESCO, 2011). Esta revisão permite introduzir uma nova visão de cidades históricas vivas contra a noção estática monumentalista do passado (Van Oers, 2013). Basicamente, esta nova visão está virada para a gestão do património em benefício das comunidades locais atuais e do futuro e inclui: (i) a necessidade constante de adaptação e modernização em reconhecimento dos ciclos de vida das cidades; (ii) o envolvimento comunitário e dos decisores na gestão do património, o que implica negociação e resolução de conflitos; (iii) a mudança da noção de património, que necessita do alargamento da sua abordagem (idem, 2013: 10). Esta visão tem relação com o conceito de proteção e transformação descrito por Ana Pereira Roders (2013) que, na prática, reconhece que a mudança pode ocorrer no tecido do património edificado, desde o período da inscrição na 


\subsection{As Classes do Património Edificado}

A definição das Classes do Património Edificado foi feita com a ajuda da Faculdade de Arquitetura e Planeamento Físico da Universidade Eduardo Mondlane [FAPF-UEM], cuja liderança coube ao seu anterior diretor, professor Luís Lage, com o apoio do professor Júlio Carrilho. O trabalho comportou a elaboração de dois regulamentos, entre 2014 e 2016: um geral e outro específico para a llha, sob a supervisão do jurista Carlos Serra, em colaboração com a Direção Nacional do Património Cultural e com o GACIM, ambos do Ministério superintende da área da cultura. Houve também trabalho de campo na llha, do qual resultou a elaboração do catálogo dos edifícios classificados da Ilha (Decreto n. ${ }^{\circ}$ 54/2016, de 28 de novembro). A fase final da elaboração dos regulamentos, em 2016, contou com a supervisão do Gabinete Jurídico do Ministério da Cultura e Turismo.

A tabela que se segue resume as Classes do Património Edificado e os correspondentes níveis de intervenção permitidos de acordo com a Política de Monumentos (Resolução n. ${ }^{\circ}$ 12/2010). À Fortaleza de São Sebastião (fig. 2) foi atribuída a Classe $A+$, onde são permitidas a conservação e o restauro que visa garantir a preservação do seu significado cultural.

\begin{tabular}{|c|c|c|}
\hline Classes & Definição & Nível de intervenção \\
\hline A+ & $\begin{array}{c}\text { Com Valor Universal } \\
\text { Excecional }\end{array}$ & Conservação e Restauro \\
\hline A & Com Valor Elevado & Conservação e Restauro \\
\hline B & Com Valor Médio & Reabilitação \\
\hline C & Com Valor Limitado & Reconstrução \\
\hline D & Com limitado valor individual & Reconstrução \\
\hline
\end{tabular}

Tabela demonstrativa das Classes do Património Edificado e níveis de intervenção (tabela simplificada no âmbito da apresentação do Decreto ao Conselho de Ministros em 2016)

O modelo de atribuição de classes do património edificado pode ser facilmente usado e evita os riscos de subjetividade no ato da emissão de pareceres sobre as intervenções a serem efetuadas. Contudo, a implementação destas classes deve ser rigorosamente complementada pela observância das recomendações da UNESCO (2008), conforme 
previsto no Decreto 54/2016, de 28 de novembro, nomeadamente a necessidade de este órgão ser consultado pelo Estado Membro da Convenção antes de qualquer intervenção.

\section{CONCLUSÃO}

Não obstante o tema apresentado ser específico para o património edificado, foram levadas em conta outras designações de contextualização genérica e legal de património cultural, ou de bens culturais imóveis.

A reflexão sobre o sistema de gestão do património edificado da llha foi alvo de vários debates, particularmente a nível de um seminário temático promovido pelo Ministério da Cultura e Turismo, em 2015, em colaboração com a FAPF-UEM e com o apoio da Embaixada de Espanha. Participaram no seminário vários técnicos do património cultural vindos de quase todo o país, assim como os estudantes do Curso de Arqueologia e Gestão do Património Cultural da Faculdade de Letras e Ciências Sociais da UEM. A colaboração das universidades na gestão do património cultural, particularmente o edificado, é importante porque ajuda a resolver o problema da carência de quadros qualificados nesta área.

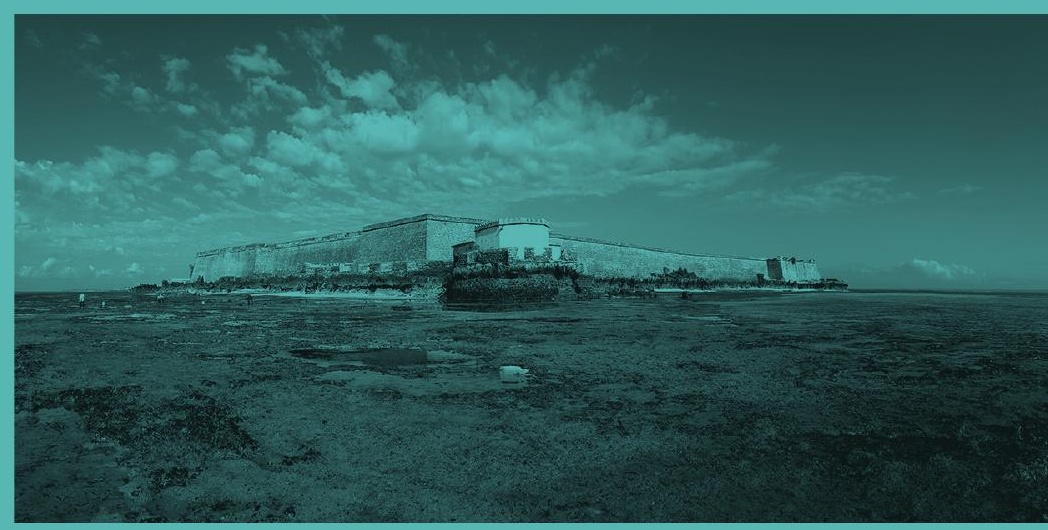

A Fortaleza de São Sebastião é um dos poucos monumentos da llha que beneficiou de uma intervenção substancial, embora numa fase inicial de estabilização da sua estrutura, por iniciativa do Governo de Moçambique, com o apoio do Governo do Japão, da União das Cidades Capitais de Língua Portuguesa [UCCLA], do Instituto 
Português de Apoio ao Desenvolvimento [IPAD], do Governo da Flandres e do Governo da Holanda (Eloundou \& Weydt, 2009). A fortaleza da Ilha, por também ser o maior monumento nacional, tem despertado o interesse de várias instituições, nomeadamente para fins socioculturais, didático-científicos e turísticos. O sistema de gestão aqui discutido possibilita a tomada de decisão de forma célere sobre o método de intervenção neste conjunto, com base nas classes do património, assim como sobre qual a instituição de gestão e os usos compatíveis, salvaguardando o seu valor universal excecional.

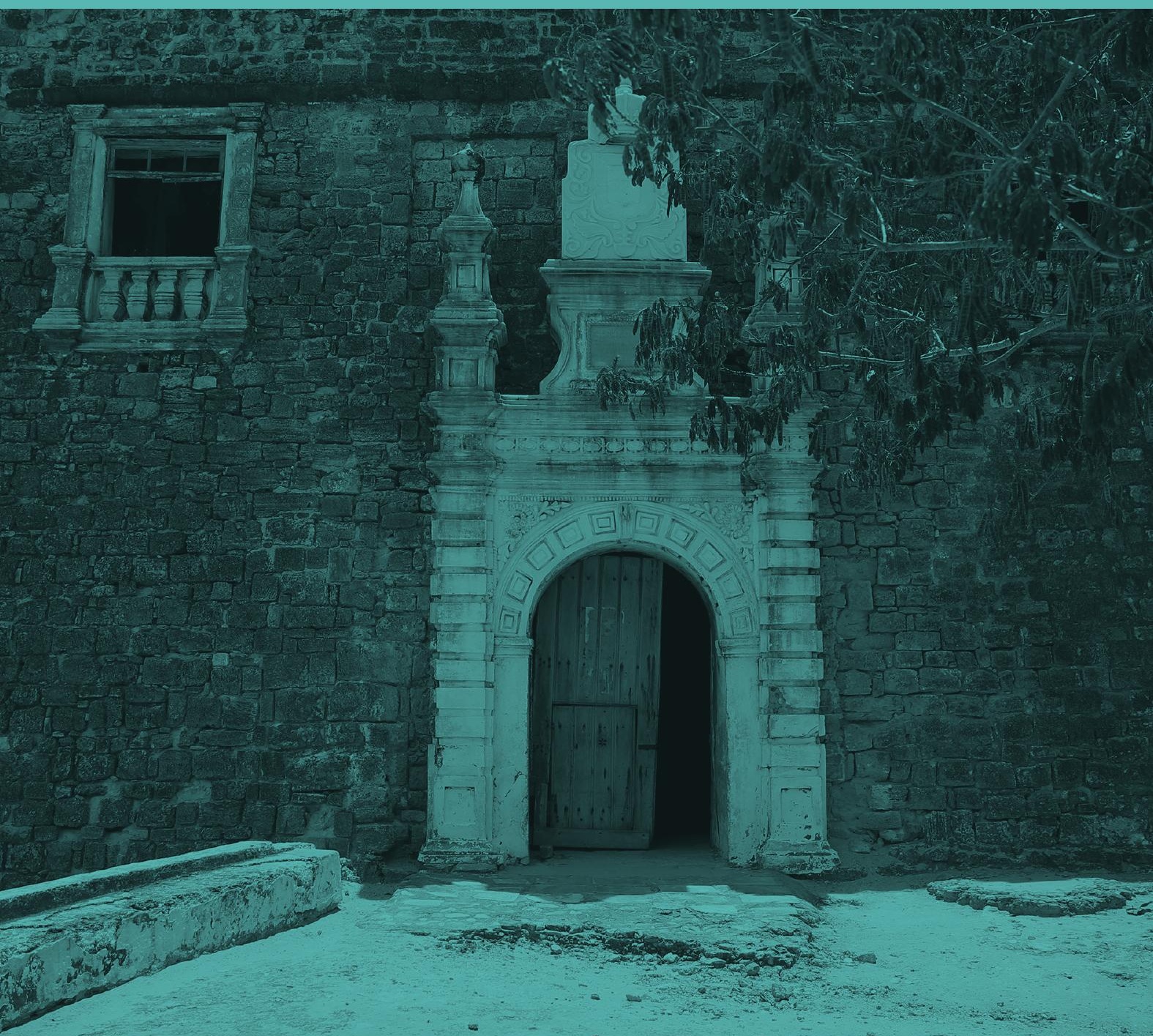




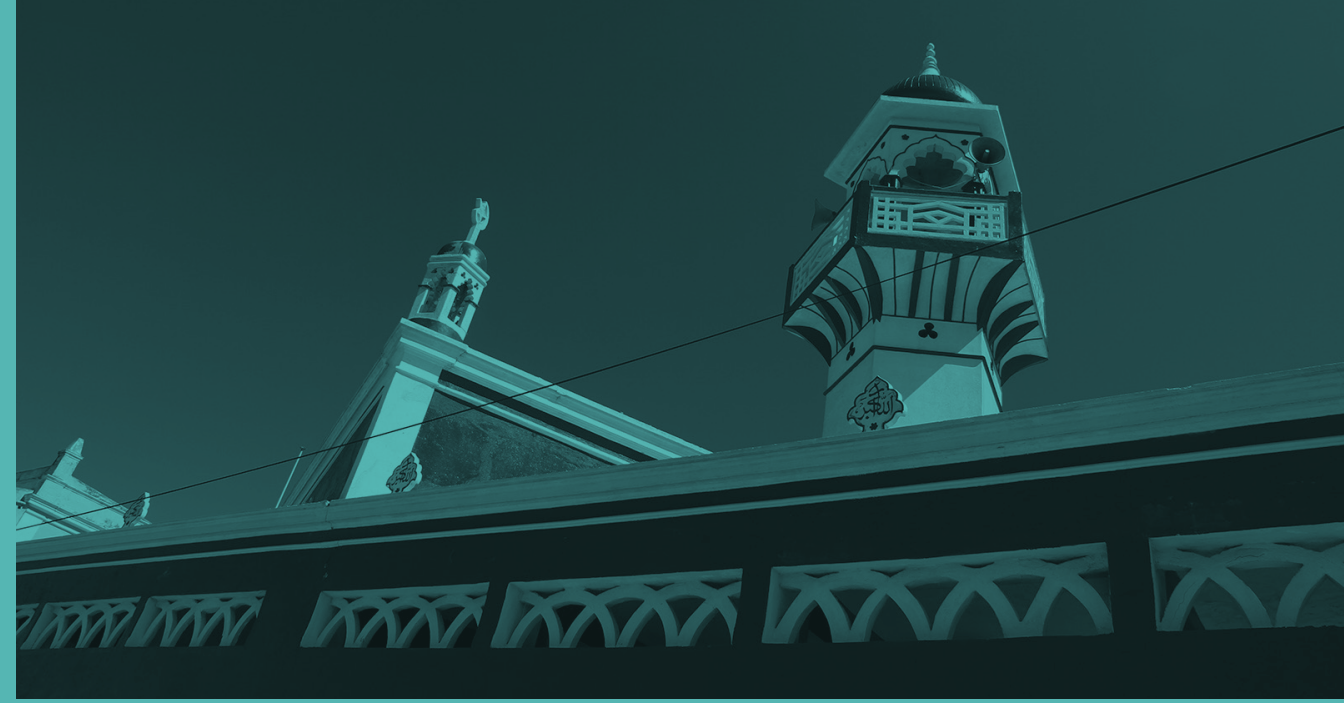

O sistema de gestão discutido levou em conta a atual abordagem da UNESCO, que considera as Cidades Históricas Vivas contra a visão estática monumentalista do passado, em benefício das comunidades locais. Contudo, é indispensável que esta nova abordagem seja monitorizada, mediando os limites entre a desejável mudança e a salvaguarda da integridade e da autenticidade, conforme definido com a inscrição da llha de Moçambique na Lista do Património Mundial da UNESCO.

A discussão sobre o sistema de gestão do património edificado da Ilha, aqui apresentada, não está concluída, devendo ainda contemplar a articulação de várias leis existentes em Moçambique nas áreas do património cultural e natural, alargando-se para os dispositivos normativos (como as posturas camarárias e as formas de implementação) através de memorandos, acordos e outras, no quadro das parcerias público-privadas.

Durante as celebrações do $10^{\circ}$ aniversário do Fundo Africano para o Património Mundial, que decorreu na África do Sul em 2016, foi também vincada a necessidade da combinação das várias convenções da UNESCO que protegem o património Mundial, para um sistema de gestão mais eficiente, nas suas vertentes tangível e intangível. Para além da Convenção de 1972 na discussão futura do sistema de gestão do património edificado, afiguram-se pertinentes outras convenções, designadamente sobre o Património Cultural Intangível (UNESCO, 2003) e sobre a Diversidade das Expressões Culturais (UNESCO, 2005). Estas Convenções são o veículo de transmissão de conteúdos e da interação cultural com vários povos, no que ao património edificado da llha diz respeito. 


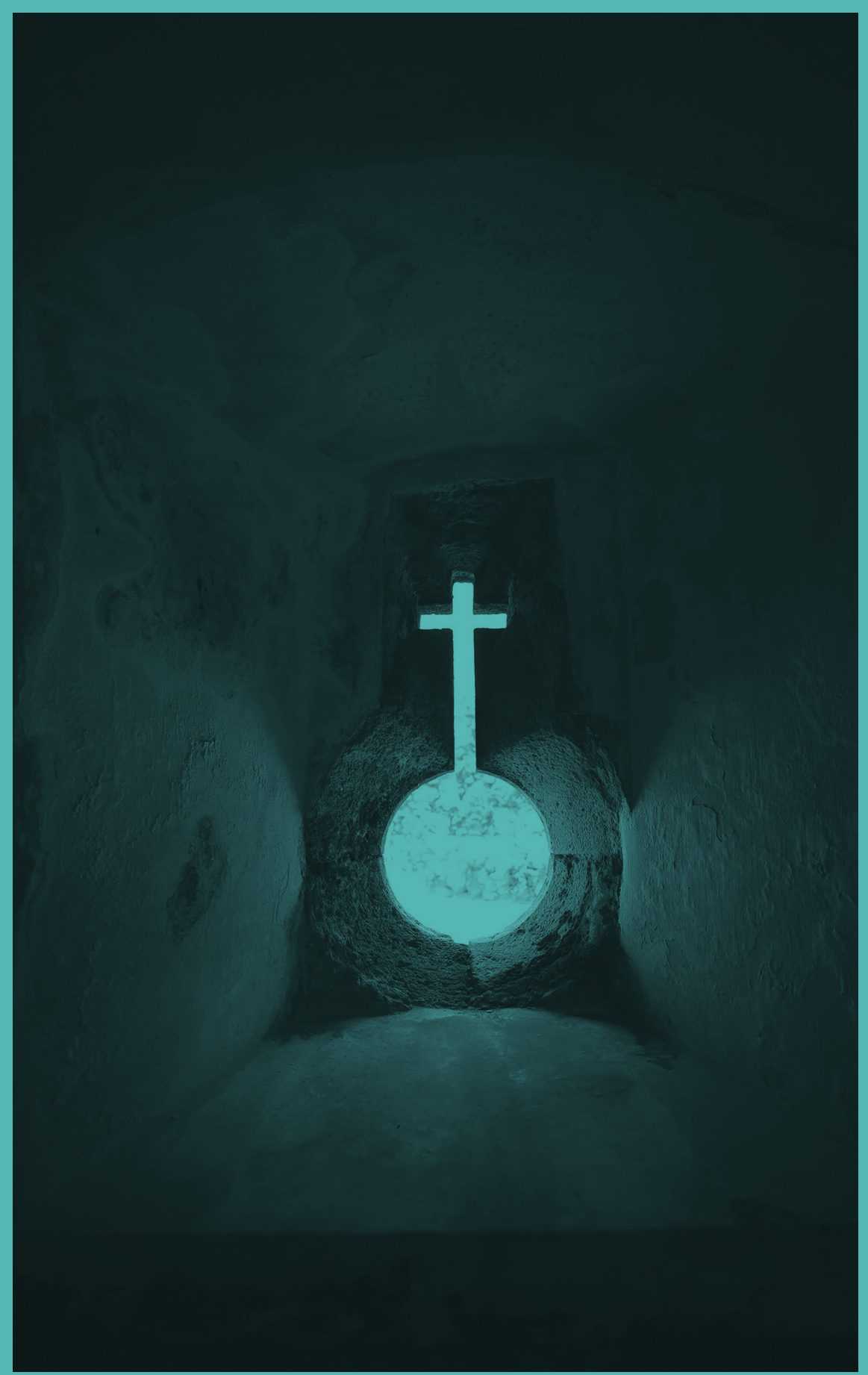




\section{REFERÊNCIAS BILBIOGRÁFICAS}

Decreto $n .{ }^{\circ}$ 27/2006 de 13 de julho (aprova o Estatuto Específico da llha de Moçambique).

Decreto $n .{ }^{\circ}$ 28/2006 de 13 de julho (cria o Gabinete de Conservação da llha de Moçambique e aprova o respetivo Estatuto Orgânico).

Decreto $n$. $^{\circ}$ 54/2016, de 28 de novembro (aprova o Regulamento sobre a Classificação e Gestão do Património Edificado e Paisagístico da llha de Moçambique. Boletim da República n. ${ }^{\circ} 142$ (I)).

Decreto $n$. ${ }^{\circ 5} / 2016$, de 28 de novembro (aprova o Regulamento sobre a Gestão de Bens Culturais Imóveis. Boletim da República n. ${ }^{\circ} 142$ (I)).

ELOUNDOU, Lazare; WEYDT, Jana (eds.) (2009), Reabilitação da Fortaleza da Ilha de Moçambique. Paris: UNESCO World Heritage Centre.

JOPELA, Albino (2006), Custódia tradicional do património arqueológico na província de Manica: experiências e práticas sobre as pinturas rupestres no Distrito de Manica, 1943-2005. Dissertação de Licenciatura, apresentada ao Departamento de História da UEM, Maputo.

JOPELA, Albino (2014), "Definição de conceitos-chave", in Solange Macamo e Albino Jopela (coords.), Manual de Conservação do Património Cultural Imóvel em Moçambique. Maputo: Ministério de Cultura, Direção Nacional de Património Cultural.

JOPELA, Albino; RAKOTOMAMONJY, Bakonirina (coords.) (2014) Plano de Gestão e Conservação da Ilha de Moçambique 2010-2014. Maputo: Ministério da Cultura.

Lei . $^{\circ} 10 / 88$ de 22 de dezembro (determina a proteção legal dos bens materiais e imateriais do Património Cultural Moçambicano. Boletim da República n. 50 (I Série)).

MACAMO, Solange (coord.) (2014), Ilha de Moçambique, Património Mundial. Maputo: Ministério da Cultura.

MACHADO, Jurema; BRAGA, Sylvia (2010), Comunicação e Cidades Patrimônio Mundial no Brasil. Brasília: MONUMENTA, IPHAN.

NDORO, Webber; KIRIAMA, Herman (2008), "Management mechanisms in heritage legislation" in Webber Ndoro et al. (eds.), Cultural Heritage and the Law. Protecting Immovable Heritage in English-Speaking Countries of Sub-Saharan Africa. Paris: UNESCO World Heritage Centre, 53-64.

NGUIRAZI, Teodato (2008). Conservation of Traditional Buildings on the Island of Mozambique: A Case Study of Macuti City. Harare: University of Zimbabwe. 
OERS, Ron van (2013), "Swahili Historic Urban Landscapes-Apllying HUL in East Africa" in Ron van Oers e Sachiko Haraguchi (eds.), Swahili Historic Urban Landscapes. Report on the Historic Urban Landscape Workhops and Field Activities on the Swahili Coast in East Africa 2011-2012. Paris: UNESCO World Heritage Centre, 6-19.

Resolução 12/2010 (aprova a Política de Monumentos, Boletim da República $\mathrm{n}^{\circ} 59$, de 27 de abril de 2010).

Retrospective Statement of Outstanding Universal Value for Island of Mozambique (2011). Paris: UNESCO World Heritage Centre.

RODERS, Ana Pereira (2013), "Lessons from the Island of Mozambique on Limits of Acceptable Change" in Ron van Oers e Sachiko Haraguchi (eds.), Swahili Historic Urban Landscapes. Report on the Historic Urban Landscape Workhops and Field Activities on the Swahili Coast in East Africa 2011-2012. Paris: UNESCO World Heritage Centre, 20-40.

ROSSA, Walter; RIBEIRO Margarida Calafate (2015), "Modos de Olhar" in Walter Rossa e Margarida Calafate Ribeiro (orgs.), Patrimónios de Influência Portuguesa: modos de olhar. Coimbra: Imprensa da Universidade de Coimbra, 11-35.

Second Cycle of the World Heritage Periodic Reporting for Africa (2010). Subregional meeting for Southern Africa. Windhoek: Namibia.

Secretaria de Estado da Cultura - Moçambique/ Arkitektskolen I Aarhus 1985. Ilha de Moçambique - Relatório/ Report 1982-85 ("Livro Azul").

UNESCO (1972), Convenção para a Protecção do Património Cultural e Natural Mundial. Paris: UNESCO World Heritage Centre.

UNESCO (2003), Convenção para a Salvaguarda do Património Cultural Intangivel. Paris: UNESCO World Heritage Centre.

UNESCO (2005), Convenção sobre a Diversidade das Expressões Culturais. Paris: UNESCO World Heritage Centre.

UNESCO (2008), Operational Guidelines for the Implementation of the World Heritage Convention. Paris: UNESCO World Heritage Centre.

UNESCO (2011), Recomendação sobre a Paisagem Urbana Histórica. Paris: UNESCO World Heritage Centre.

UNESCO (2013), Managing Cultural World Heritage. World Heritage Resource Manual. Paris: UNESCO World Heritage Centre. 